Revista Destaques Acadêmicos, Lajeado, v. 12, n. 2, 2020. ISSN 2176-3070

DOI: http://dx.doi.org/10.22410/issn.2176-3070.v12i2a2020.2619

http://www.univates.br/revistas

\title{
INFLUÊNCIA DA FAMÍLIA NA APRENDIZAGEM DE ESTUDANTES DE UMA ESCOLA PRIVADA MATO- GROSSENSE
}

\author{
Isabel Aparecida Teixeira ${ }^{1}$, Ana Claudia Tasinaffo Alves ${ }^{2}$, \\ Marcelo Franco Leão ${ }^{3}$
}

\begin{abstract}
Resumo: A influência da família na aprendizagem tem fomentado uma crescente preocupação dada a sua relevância para a educação e o desenvolvimento de estudantes, causando desafios na aprendizagem de crianças. O presente texto é resultado de uma pesquisa que teve como objetivo compreender a influência da família na superação de dificuldades de aprendizagem de crianças de uma escola privada mato-grossense na disciplina de Ciências. Trata-se de um estudo de caso, feito a partir de uma intervenção pedagógica realizada em uma escola privada de Confresa/MT. Essas atividades iniciaram em 2017 e deram continuidade até 2019. Foram muitas as situações observadas, porém, optou-se por relatar no presente texto, três estudantes que participaram da intervenção pedagógica que envolveu a professora, esses estudantes e familiares. Sendo assim, é evidente a importância da participação da família em todas as etapas da vida, contribuindo para o desenvolvimento social e intelectual dos estudantes.
\end{abstract}

Palavras-chave: Dificuldades de aprendizagem; Família; Intervenção pedagógica.

\section{INTRODUÇÃO}

Ao refletir sobre os desafios de aprendizagem de estudantes que não passam por dificuldades financeiras, ou seja, que aparentemente não convivem com a fome, com conflitos familiares e pertencentes a um nível social que lhes permite ter condições financeiras razoáveis, percebe-se que, mesmo assim, muitos deles não conseguem se desenvolver plenamente no que diz respeito sua aprendizagem escolar.

1 Graduada em Pedagogia (INET) e Especialista em Ensino de Ciências pelo IFMT Campus Confresa.

2 Doutora em Educação em Ciências e Matemática (REAMEC), professora do IFMT Campus Confresa.

3 Doutore em Educação em Ciências (UFGRS), professor do IFMT Campus Confresa. 
Contemplando este problema, nota-se a necessidade de compreender como se estabelece relações entre a família e a sala de aula, como fatores que contribuem para a construção do processo de aprendizagem destes estudantes. De acordo com Pilleti, (1993, p. 69): "o aluno pode ter dificuldades em aprender por estar com fome ou cansado, por estar inseguro quanto ao futuro, por estar isolado na família ou no grupo de colegas, por sentir-se desprezado ou inferiorizado".

No entanto, se as condições financeiras são favoráveis, seria a família um fator que interfere no desenvolvimento cognitivo? Nesse sentido, o presente texto é fruto de uma investigação que teve como objetivo compreender a influência da família na superação de dificuldades de aprendizagem de crianças de uma escola privada de Confresa/MT. Trata-se de um estudo de caso sobre os desafios na aprendizagem de estudantes de classe econômica favorável, que objetivou compreender os desafios na aprendizagem de crianças de uma escola privada. O mesmo foi desenvolvido por meio de uma intervenção pedagógica ao longo de dois bimestres na disciplina de ciências, no ano de 2017.

A proposta buscou conhecer os motivos de possíveis problemas de aprendizagem na disciplina de Ciências de estudantes nos espaços de uma escola privada. Para tanto, foi necessário estudar e escrever sobre a contextualização da escola na qual foi realizada a pesquisa, a legislação que determina o dever da família e da escola, os desafios de aprendizagem em escolas privadas, modelos de famílias dos dias atuais, a escola, o professor e a importância da parceria entre a família e a escola, discussões que subsidiarão a análise das observações realizadas durante todo o período da pesquisa.

O referido estudo de caso esclarece que todos os estudantes que participaram da pesquisa, vêm de família tradicional, que consiste em pai, mãe e filhos. No entanto, acredita-se que qualquer criança, independentemente da situação ou tipo de famílias, venha a ter desafios para superar quanto a aprendizagem escolar. Assim, uma hipótese é que as dificuldades dos referidos estudantes se devem aos mesmos serem indisciplinados, ou devido ao tempo que faltam aos pais no acompanhamento das atividades escolares de seus filhos, tanto aquelas que exigem a presença da família no cotidiano escolar, quanto nas rotinas diárias em domicílio.

\section{RELAÇÃO ENTRE FAMÍLIA E EDUCAÇÃO FORMAL}

Todos os documentos educacionais nacionais, inclusive a Constituição Federal e o Estatuto da Criança e do Adolescente (ECA), mencionam que a educação é um dever da família e do estado. Também fica assegurado pela Lei de Diretrizes e Bases da Educação (LDB), lei No 9.394 (BRASIL, 1996), em seu artigo $2^{\circ}$, que essa obrigação é em primeiro lugar da família para depois ser mencionado o estado. Nesse sentido, é possível compreender que não é a 
família que ajuda a escola na educação dos filhos, mas sim a escola que ajuda a família.

No entanto, o que se percebe é a inversão dos papeis, ou seja, as famílias acabam deixando a cargo da escola as obrigações e responsabilidades que lhes competem. Para agravar essa situação, muitas famílias estão confundindo o significado de criar com o de educar, atribuindo exclusivamente às escolas as responsabilidades de educar, que também é sua (FURTADO, 2015).

Pressuposto que o processo de aprendizagem se inicia dentro do seio familiar, pois é nos primeiros contatos sociais em casa que a criança aprende valores éticos, gentilezas, interação e conviver com as diferenças. Por isso, é de suma importância que os pais tenham consciência que o papel de a escola é de potencializar o indivíduo e gerar aptidões para viver em sociedade.

Assim, é preciso aprofundar os estudos sobre os significados das palavras "educar e criar". Criar é o processo em que os pais iniciam as responsabilidades desde o nascimento da criança, oferecendo condições de vida, onde as crianças devem receber o necessário para sua sobrevivência (ABBAGNANO, 2007). Esta é a fase na qual se aprende a andar, falar, comer, apreciar as novidades inseridas no cotidiano. Enfim, é a parte em que tudo que a criança faz é lindo.

Porém, devemos observar que o educar inicia-se também neste período, onde devemos direcionar a consciência de valores éticos, que o ato de educar começa em casa e que pais também são educadores (ABBAGNANO, 2007). Sendo assim, "educar e criar" precisa andar junto, esta é a condição para não criamos adultos infantis, incapazes de tomar decisões, respeitar regras, entender que problemas existem, tornando-os despreparado para o convívio em sociedade e para viver no mundo. Consequentemente criar: cuidar das necessidades básicas da criança para que cresça forte e saudável, e educar: ensinar os princípios de ética e civilidade para a inserção do indivíduo em sociedade, são o caminho para idealizarmos como será a geração futura.

As famílias vêm passando por grandes transformações ao longo do tempo. Um fator que pode estar relacionado também com este caso é a inserção da mulher no mercado de trabalho. De acordo com Schwyzer (2011), antigamente havia concepções diferentes de famílias, provavelmente nossos avós eram crianças nessa época. Poucos casais se separavam, mesmo sendo infelizes traziam consigo os mandamentos religiosos e as culturas mais antigos: "O que Deus uniu o homem jamais separa". Geralmente a mulher se dedicava a cuidar somente dos filhos, casa e marido, não tinham atividades profissionais fora do lar que lhes trouxesse estabilidade financeira, nessa lógica, as mulheres tinham dificuldades de se sustentar sozinhas, além do preconceito velado no ideário social fator este que dificultava a separação.

A família tradicional: eram famílias geralmente numerosas, centrada na autoridade do patriarca, mas comum até a primeira metade do século XX. Considerados "familiares" não estavam sós os pais e filhos, mas todo o entorno 
familiar (avós, tios, primos, etc.), e as relações eram baseadas nos conceitos morais e autoritários da época (SCHUWYZER, 2011).

A família nuclear: ou psicológica, é aquela surgida a partir da metade do século XX, fundamentada basicamente em pai, mãe e poucos filhos. As relações não são mais tão autoritárias, e o conceito de família engloba um núcleo mais caseiro (SCHUWYZER, 2011).

Família pós-moderna está inserida em nosso cotidiano, aquela em que não existem regras básicas de parentesco. Como exemplo, filhos morando com só um dos pais (devido ao divórcio), casais sem filhos, uniões homossexuais, etc. Enfim, g.rande ou pequena, no passado ou no presente, vivendo no Brasil ou em qualquer parte do mundo, as famílias se organizaram de diversos modos (SCHUWYZER, 2011).

Nos dias atuais, há grandes desafios na área da educação, um exemplo são os elevados índices de violência escolar, neste contexto tendemos a refletir se a ausência da família na vida escolar de seus filhos pode estar relacionada a tal fator. É possível observar no cotidiano escolar que na maioria das vezes o compromisso das famílias é somente de matricular seus filhos na unidade escolar.

Nota-se a ausência da maioria dos pais em reuniões, eventos escolares onde os estudantes fazem apresentações, acompanhamento de tarefas extraescolares, reuniões individuais para tratar de assuntos exclusivos de seus filhos, pois quando os mesmos são chamados à escola por diversas vezes e ainda assim não comparecem (FURTADO, 2015).

Nesta acepção, tem se tornado indefinido para os estudantes de quem é a responsabilidade de educar, dos pais ou da escola? Verifica-se que uma grande maioria dos pais se esquecem de que seus filhos crescem, existem temáticas que devem ser abordadas pelos pais, se a criança aprende no seio familiar os princípios básicos, torna-se mais tranquilo a inserção e interação da mesma em grupos sociais.

Segundo Oliveira (2006), é a partir da herança genética adquirida que as características contribuirão na aprendizagem no decorrer de nossas vidas com o convívio familiar, social e escolar. Steinberg $(2005$, p. 3) enfatiza que: "é uma tendência natural das crianças, copiarem tudo o que os adultos fazem, principalmente quando os adultos são os pais".

Nesse contexto, em que as crianças copiam os adultos pode-se discutir a afetividade, que de acordo com Mahoney e Almeida (2005) tem relação com à capacidade que nós seres humanos temos de sermos afetados pelo mundo externo e interno. Elas ocorrem por meio das sensações agradáveis ou não, e ainda o que expressa a afetividade são os sentimentos que podem ser via linguagem verbal.

Constata-se deste modo que toda criança em algum momento da vida, admira todas as coisas feitas por seus pais, podemos representar este momento 
como um reflexo do espelho, podendo moldar o caráter desta criança para ser o indivíduo bem-sucedido socialmente. Porém, se o reflexo for o oposto de caráter e dignidade o indivíduo pode se tornar extremamente inadequada para o convívio em sociedade, mas, se refletir do espelho dos pais, boa conduta, facilitará o seu desenvolvimento emocional e social (RIBEIRO, 2010, LEITE, 2012).

Ainda segundo o autor supracitado, o indicado é explorar a afetividade como elemento que influencia nas relações e automaticamente no desenvolvimento dos indivíduos. Assim, é indicado que os pais evidenciem para seus filhos que o respeito como a base essencial para a convivência em sociedade independentemente da cor, raça ou idade, ensinar os fundamentos de sexualidade e sua função, que violência gera violência, drogas é um caminho sem volta, os pais nunca devem permitir que seus filhos aprendessem estes princípios de maneira incorreta, mas, na hora certa buscar a melhor estratégia para sanar as curiosidades sobre todas as temáticas que a crianças vier a abordar.

De acordo com as palavras de Cury (1958, p. 13 e 14):

A ONU detectou que há 800 milhões de pessoas famintas, ingerindo menos de 2 mil calorias diárias. Um desastre. Mas, o que a ONU não pesquisou é que há bilhões de crianças e adultos emocionalmente famintos, vivendo miseravelmente, não poucos morando em palácios ou belos condomínios residenciais. Atualmente, crianças, adolescentes, jovens e adultos precisam de muitos estímulos para sentirem migalhas de prazer. Na era da insatisfação, traficantes não vendem drogas, oferecem drogas para personalidades insatisfeitas. Uma emoção dramaticamente vazia e angustiada é um comprador em potencial.

Nota-se que o autor considera que a sociedade detecta uma variedade de problemas sociais, tais como: fome, drogas, dificuldades na aprendizagem, compradores compulsivos, adolescentes que se cortam, entre outros problemas que vivenciamos no cotidiano. Porém, ela não se atenta que tais atitudes estão relacionadas às nossas maiores frustações.

Aponta-se que o verdadeiro caráter implica em racionalidade, compreensão, equilíbrio e justiça, elementos estes que devem fazer parte de uma pessoa. A criança que não conhece os problemas morais só pode ser amoral. O caráter aparece quando as decisões para o bem-estar de todos ficam acima dos interesses pessoais. Outro fator que requer muita atenção da família na colaboração da educação das crianças é a falta de limites (STEINBERG, 2005).

Ainda diz Steinberg, (2005) que uma das maiores problemáticas encontradas por profissionais da educação é a falta de limites, desrespeito na sala de aula e desmotivação dos estudantes. Nunca se observou tantos profissionais da educação cansados, estressados e, muitas vezes, doentes física 
e mentalmente. Esta indisciplina da maioria dos estudantes, eventualmente consequência de uma má educação imposta por o descontrole emocional familiar, que não impondo limites criam crianças mimadas que querem tudo, não divide nada com ninguém, rebeldes e teimosas.

Esta situação traz grandes complicações no ambiente escolar, pois, os mesmos conflitos gerados com os pais refletidos na escola, com professores e colegas, sempre com o intuito de conquistar o objetivo desejado. Conflitos estes que vem a enriquecer os problemas de dificuldades de aprendizagem do estudante. Gerando um sentimento de impotência e frustração que contribui nas dificuldades presentes na vida escolar (MAHONEY; ALMEIDA, 2005; RIBEIRO, 2010).

Imagina quantas coisas é de responsabilidade da escola, oferecer merenda, oferecer vários conteúdos, discutir os valores da sociedade, fazer formação ética, cuidar das crianças, nos acarretamos de tantas funções em nosso cotidiano, sem nos atentar que estas crianças vêm de família indisciplinada, e a primeira pessoa adulta em sua vida que lhe diz o primeiro não acaba sendo o professor. Sendo assim, fica evidente a necessidade de manter uma relação saudável na escola, principalmente para evitar conflitos com o professor, principalmente relacionado ao estabelecimento de limites (MAHONEY; ALMEIDA, 2005).

Segundo Furtado (2015), toda criança deve ser autodisciplinada, as disciplinas devem ser divididas por etapas nas quais as crianças devem obedecer regras, estabelecer o diálogo com o intuito de estipular que tudo que vivenciamos têm seu tempo e ter responsabilidades em cumprir tarefas que lhes foram ofertadas. Seria importante que os pais pudessem usar tudo que é atrativo para a criança como seu aliado, a proximidade dos pais no cotidiano da criança contribuí nas discussões e explicações sobre os conteúdos adequados para todas as etapas. Destarte, a criança compreende com clareza, facilitando para que as mesmas não questionem as decisões tomadas pelos pais.

Para a autora supracitada, a criança deve ter contato com todas as coisas que moldam seu caráter, os pais devem também estabelecer que, algumas responsabilidades pudessem ser momentâneas e outras durassem para sempre. Se dermos exemplos nesta situação podemos citar que, o simples fato de guardar os brinquedos é momentâneo e a responsabilidade de se respeitar carrega-se por todas as etapas da vida do ser humano. Furtado (2015) ainda ensina como preparar seu filho para o convívio em sociedade, ensinando que não devemos gastar tudo que temos às vezes o "não" trabalha a nosso favor, e uma regra muito importante, pais devem ensinar seus filhos, praticando tudo aquilo que lhes ensina.

Para o desenvolvimento da criança deve ser considerado a afetividade, que de acordo com Leite (2012, p. 360) é um processo de desenvolvimento humano que envolve "vivências e formas de expressão mais complexas, desenvolvendo-se com a apropriação, pelo indivíduo, dos processos simbólicos 
da cultura, que vão possibilitar sua representação". Ribeiro (2010, p. 403) considera que "a afetividade é impulsionada pela expressão dos sentimentos e das emoções e pode desenvolver-se por meio da formação".

Esclarecendo que tudo o que os pais ensinam para seus filhos deveria ser com o intuito de contribuir na inserção da criança no convívio em sociedade, de aprender que nem tudo que seus olhos veem com perfeição é perfeito aos olhos dos outros, aprender que os pais educam por que amam, que quando são castigados fizeram coisas indevidas, devem abstrair o conhecimento e utilizarem para fazer o certo (LEITE, 2012).

\section{CONTEXTUALIZAÇÃO DA ESCOLA}

A referida pesquisa foi realizada em uma escola localizada na área urbana no município de Confresa/MT, licenciada para funcionamento do Ensino Fundamental I e II e tendo como turnos de funcionamento, matutino e vespertino. A unidade escolar possui abastecimento de água tratada, da rede de distribuição do município e possui um poço para atender em situações emergenciais propiciando assim um bom andamento das atividades escolares. A coleta de lixo é realizada pela prefeitura municipal três vezes por semana.

A filosofia da escola está baseada no fato de que ela seja o instrumento que norteia as práticas de ensino. Assim, procurou-se elaborar um projeto que refletisse a realidade da comunidade escolar. Partiu-se do pressuposto que a educação escolar contribui com a formação sistemática, planejada e continuada das crianças, adolescentes e jovens, durante um período contínuo de tempo, diferenciado de processos educativos que ocorrem em outras instâncias como família, trabalho, mídia e tantos outros espaços de construção de conhecimento e valores para o convívio social. Assim sendo, entende-se que a escola exerce forte influência nas atitudes das pessoas. Essas atitudes podem ser passivas ou crítica/reflexiva diante das dificuldades que venham surgir no contexto social mais amplo (PPP, 2017).

A implementação das atividades de intervenção desta pesquisa, surgiu de investigações efetivadas na unidade escolar, por meio de reuniões com o corpo docente e discente, envolvendo também a comunidade escolar, visto que os processos educativos não são tarefas que se façam solitariamente.

A partir da convivência diária com os estudantes observa-se que os desafios na aprendizagem estão longe de ser uma realidade apenas de instituições de ensino públicas, onde se recebem estudantes de todos os níveis sociais, que passam por dificuldades na aprendizagem tanto na leitura, quanto na escrita e também na socialização com outras pessoas (PPP, 2017).

Na escola verificou-se que há situações de estudantes que provavelmente não passam por dificuldades financeiras, ou seja, não convivem com a fome, com conflitos familiares e seus níveis sociais lhes permitem ter uma condição melhor de estudos e acesso a materiais e tecnologias, no entanto, mesmo assim 
não conseguem se desenvolver no que diz respeito a sua aprendizagem escolar. Tais situações que ocorrem no espaço escolar dentro da sala de aula, e vão sendo levantadas em momentos de reflexão juntamente com a equipe pedagógica, e nos encontros de formação continuada dos profissionais da escola, sempre no intuito de encontrar soluções para os problemas destes estudantes.

\section{PERCURSO METODOLÓGICO}

O presente estudo configura-se como um estudo de caso, descritivo e exploratório, cuja abordagem é qualitativa. Para Gil (2010), esse tipo de estudo é indicado para levantar informações sobre uma determinada situação, fenômeno ou comportamento, sendo considerada a subjetividade dos envolvidos.

O caso foi estudado a partir de uma intervenção pedagógica nas aulas de ciências em uma escola privada. Após os dois primeiros bimestres de 2017, na disciplina de ciências, foram observadas dificuldades de aprendizagem em estudantes do primeiro ano do Ensino Fundamental, diante das dificuldades observadas, foram promovidas atividades para os estudantes junto com os familiares nos bimestres seguintes.

O método constituiu-se na busca de sanar a dificuldades encontradas por estes estudantes, o professor observou que os estudantes necessitavam de aulas extraclasse, com novas estratégias para consolidar as necessidades dos estudantes envolvidos na intervenção. Sendo assim foi elaborado um cronograma com atividades lúdicas para diferenciar a rotina escolar e tornála mais tranquila, foram utilizados alguns jogos para estimular o estudante a participar, neste momento o papel do professor é fazer com que o estudante aprenda brincando. Os pais participavam de aulas lúdicas na maioria das vezes, contribuíam em algumas aulas práticas e atividade extraclasse. Nas oficinas foram ofertadas aulas práticas com jogos, brincadeiras e aulas de campo uma forma de consolidarmos a importância do contato com a natureza e sair com os estudantes do ambiente escolar. A interação nas aulas de campo era entre professor e colegas onde coletavam materiais para fortalecer a aprendizagem do conteúdo trabalhado na disciplina de ciências.

Neste aspecto, foi importante o fato de o professor buscar metodologias diferenciadas, promovendo um engajamento de todos os atores na busca de solucionar as dificuldades dos estudantes. As estratégias de ensino utilizadas nas aulas de ciências foram elaboradas de forma a despertar a curiosidade dos estudantes e os tornarem criativos por conta da facilidade do conteúdo em relacionar a matéria com aulas práticas. A maioria das atividades foi preparada de forma, em que os pais dos mesmos participassem junto com os filhos.

Cabe ressaltar que na instituição de ensino onde ocorreu a intervenção pedagógica, a maioria dos estudantes é de família tradicional, que consiste em pai mãe e filhos, deixando a claro que não são somente crianças de famílias não consideradas tradicionais que enfrentam desafios de aprendizagem, embora 
sejam problemas muitas vezes diferentes de crianças que passam necessidades básicas, entretanto a dificuldade dos referidos estudantes podem estar relacionados a fatores como falta de tempo dos pais de estar acompanhando atividades do cotidiano escolar.

O desenvolvimento do estudo ocorreu com uma turma de $1^{\circ}$ ano e com alguns estudantes dos $6^{\circ} 7^{\circ}$ e $8^{\circ}$ ano do Ensino Fundamental, na conjuntura de professora articuladora, responsável pela organização das atividades propostas para sanar as dificuldades não solucionadas em sala de aula, neste contexto foi possível observar que alguns desses estudantes, mesmo tendo uma situação financeira bastante confortável possuem grandes dificuldades no aprendizado.

\section{RESULTADOS E DISCUSSÃO}

Os resultados obtidos permitiram identificar como desafios as dificuldades de aprendizagem, ausência da família e indisciplina, fatores que contribuem nas dificuldades na aprendizagem dos estudantes relatados na intervenção, na busca de metodologias e novas estratégias para compreender as necessidades destes estudantes.

Iniciamos a intervenção com o estudante " $X$ ", que vive aparentemente em uma família bem estruturada e conceituada, está sempre bem vestido, tem muitos brinquedos, alimenta-se bem, porém não tem domínio na escrita, nem na leitura o mesmo tinha um comportamento que pode ser considerado inadequado na escola, em sua casa e em qualquer lugar em que o mesmo esteja.

Infelizmente, neste caso a intervenção pedagógica não superou as dificuldades, pois, todos os métodos utilizados com o estudante não obtiveram resultados satisfatórios. Observou-se que o mesmo não se sentiu atraído com as novas atividades propostas.

Porém, neste caso não podemos atribuir o fracasso ao estudante, já que a proposta, da instituição foi concordada pela família, onde a mesma se propôs a contribuir, participando sempre que fosse solicitada. Mas, o estudante quase não comparecia as aulas de reforço e quando o fazia os pais os deixavam-no no portão, não entravam para saber do desenvolvimento do estudante, não compareceram as atividades coletivas. As atividades deveriam ser trabalhadas juntamente com a família e o estudante, no entanto a família não ajudava nas tarefas extraclasse, não comparecia às reuniões e sempre chegavam atrasados para buscá-lo. Estes fatores contribuíam para o estudante se tornar agressivo e desinteressado por aprender. Então a equipe optou por não forçar o estudante já que não tínhamos o respaldo da família.

Nesta circunstância as problemáticas aumentaram, o estudante se sentia muito frustrado e não queria ir mais a escola, e quando conseguíamos obter ou diálogo com o mesmo, ele chorava, dizia que era burro, pois, "sua mãe dizia", e que não adiantava vir à escola todos os dias porque que não conseguira aprender nada. Entretanto, a equipe penalizada com a situação tentou ainda 
uma nova estratégia, trabalhar a base de troca, oferecendo a escolinha de futebol já que o mesmo gostava do esporte, em troca ele teria que vir a escola todos os dias e não poderia ser agressivo com as pessoas.

A nova proposta feita ao estudante surtiu o efeito esperado, o mesmo se sentia motivado e aos poucos iniciou o processo, pois, sabia que se não melhorasse seu comportamento e não desenvolvesse as atividades não poderia jogar futebol. Ainda houve a necessidade de fazer o acompanhamento do estudante " $X$ " na maioria das vezes individualmente, principalmente quando as atividades necessitavam do acompanhamento dos pais assim, o mesmo não sofreria com a ausência deles. A partir das novas adaptações a intervenção alcançou resultados positivos com este estudante.

Essas particularidades reforçam o pensamento de Oliveira, (2006) pois, toda criança deve dominar sua agressividade para se libertar e essa libertação diminuirá as frustações, abrindo caminhos para iniciar a resolução dos problemas do estudante.

No cenário do estudante " $Y$ " observa-se que as características eram muito parecidas com o estudante " $\mathrm{X}$ ", porém, trabalhar com o estudante era mais complicado, pois, possuía dificuldades na leitura, na escrita e desenvolveu a agressividade no decorrer da intervenção pedagógica, se mostrava sempre nervoso e agressivo, sendo preocupante seu estado emocional, pois estas situações eram constantes, afetava a comunidade escolar e sua família.

A proposta foi buscar primeiramente conquistar estudante. Pois, Aquino (2019) afirma que por meio da conquista, os pais iniciam o processo de educar, que se houver amizade e parceria entre pais e filhos o processo de educar alcançará o êxito esperado. Sendo assim, o principal objetivo foi descobrir o que motivava o mesmo a ser agressivo, demorou três semanas para obtermos os primeiros rendimentos, descobriu que o mesmo gostava de diferentes tipos de jogos, neste caso iniciamos a intervenção a base de troca, se ele fizesse as atividades, nós poderíamos jogar no final da aula, assim era jogado diversos jogos como: dama, dominó, quebra-cabeça, entre outros. Com esses jogos aproveitava-se para ensinar raciocínio lógico, e foi possível perceber que houve evolução na aprendizagem.

Observou-se também que a presença materna era constante, a mãe cumpria todos os seus deveres com a escola e com o estudante, mas, o estudante ansiava a presença paterna, e o seu pai viajava muito e não conseguia participar da vida do estudante. $E$ todos os conflitos causados pelo mesmo eram com o intuito de chamar atenção do pai. Depois de longas conversas com o pai ele se propôs a participar mais da vida do estudante, contribuindo sempre que estava na cidade e até fazendo surpresa para o estudante na escola, assim que possível. Os resultados fluíram rapidamente, era possível visualizar a alegria nos olhos do estudante todas as vezes que seu pai o buscava na escola, ou participava das atividades propostas. 
Nesta sequência, observou-se que todas as atividades ofertadas ao estudante eram absorvidas com facilidade, o estudante sentia prazer em contar todos os dias que tinha feito às atividades com o pai, que tinha andando de bicicleta, jogado bola. A mãe era muito presente e participava de todas as atividades mesmo quando o pai estava presente. Observou-se também as mudanças com relação ao comportamento. Essa constatação confirma o que Ribeiro (2010) defende, de que o afeto expresso por sentimentos e emoções de pessoas próximas contribuem significativamente para a formação do estudante.

Em se tratando do estudante "W", suas características diferenciam da dos demais, o mesmo é disperso, não faz as atividades propostas, não participa das aulas, e quando as faz é tudo em seu tempo. Neste caso o estudante sentia a ausência da mãe, por ser uma mulher dinâmica viajava o tempo todo a trabalho, o estudante geralmente estava com o pai ou algum responsável, devido ser somente o casal na cidade o estudante convivia diariamente com as babás, e quase toda semana exibia brinquedos novos, roupas e calçados caros, tinha uma vasta coleção de mimos, era sempre chamado atenção por levar brinquedos caros, correndo o risco dos colegas estragarem e ter conflitos, já que o estudante raramente dividia suas coisas com os colegas.

Porém, o estudante não era agressivo, era muito calmo tanto com os professores quanto com os colegas, mas, era calado, chorava muito, não gostava de fazer nem um tipo de atividade sozinho e nem no coletivo e se houvesse insistência se isolava em um canto e chorava e não conseguíamos os resultados esperados. Em todos os casos observados neste texto, a intervenção pedagógica do estudante " $W$ " foi a que melhor se destacou entre todas.

A mãe ao ser solicitada compareceu na escola, ao ser informada do problema imediatamente se sentiu culpada por seu filho se encontrar em uma situação tão delicada, pediu um tempo de quinze dias para se organizar, e se dedicou inteiramente ao estudante, as mudanças ocorreram nas primeiras semanas em todos os aspectos leitura, escrita e socialização, eram visíveis tais mudanças que o estudante sentia necessidade de contar para a professora que tipos de atividades tinha feito com sua mãe.

Essas características reforçam o pensamento de Cury, (2003), pois, os mimos excessivos geram crianças com diversos problemas de convivência, e a maneira mais eficaz para solucionar estas dificuldades de aprendizagem são reciclarmos as criações anteriores, onde os mimos oferecidos eram beijos e abraços e priorizar seus filhos que devem ser o maior tesouro para os pais.

Porém observa-se que as dificuldades encontradas em todos os estudantes do texto tanto o " $\mathrm{X}$ ", " $\mathrm{Y}$ " e " $\mathrm{W}$ ", estão relacionadas à ausência da família evidenciando que o importante para o estudante, não é ter somente uma situação financeira confortável.

Analisando o comportamento e as atitudes dos estudantes $\mathrm{X}, \mathrm{Y}, \mathrm{W}$, percebe-se que ambos têm comportamentos diferenciados, mas os desafios na 
aprendizagem são os mesmos, dificuldade na leitura, na escrita e até mesmo na socialização. Comparando um caso ao outro se percebe que em todos os três casos, os pais são muito ocupados, trabalham o dia inteiro, são comerciantes e estão sempre viajando e não tem tempo para os filhos.

O referido estudo de caso foi inicialmente fundamentado a partir de bibliografias que oferecem auxílio na busca de metodologias adequadas e soluções para tentar sanar a dificuldades na aprendizagem dos estudantes. Assim, foi possível corroborar o pensamento de Leite (20120 que sugere a afetividade como meio que contribui para o desenvolvimento cognitivo do indivíduo, que busca em seu histórico de vida, relações e cultura um aporte para dar significado aos conhecimentos que constrói dentro da escola.

Ainda contribuiu para que os professores envolvidos na intervenção pedagógica se confirmem a necessidade que existe de que a família participe da vida escolar dos estudantes. Sendo assim, o desenvolvimento dos estudantes não depende somente bens materiais, (materiais escolares caros, roupas, comidas e brinquedos) mas, que toda e qualquer criança, necessita de carinho e atenção, independentemente de qualquer que seja seu nível social.

\section{CONSIDERAÇÕES FINAIS}

Após estudos teóricos, coleta de informações por meio de observações com três estudantes, equipe pedagógica e família, podemos afirmar que a intervenção foi abrangente pois, envolveu todo o processo educativo auxiliando os pais a entenderem a importância de participarem na vida escolar de seus filhos, com as observações realizadas antes e durante a intervenção pedagógica nas aulas de ciências, foi possível perceber a relevância da participação da família em relação ao processo de aprendizagem dos estudantes nas atividades escolares.

Mas, esclarecer que amor dos pais ou de outros adultos é uma condição indispensável para a educação da criança. Quando os pais amam os filhos, estes desenvolvem atitudes positivas em relação a si mesmo, aos outros e a vida. Os filhos aprendem a amar, verdadeiramente, amar a si mesmo, amar aos outros, amar a vida. Não basta falar que ama pois, criança aprende com atitudes e não por palavras. Não adianta disfarçar porque as crianças percebem.

A participação dos pais na vida escolar dos filhos vem somar e ajudar a superar as dificuldades dos estudantes, o mesmo se sente valorizado com a presença familiar e compreende que a parceria família e escola traz resultados positivos, a proximidade dos pais dentro do ambiente escolar traz segurança, satisfação e também a preocupação em relação ao estudante de dar o seu melhor. 


\section{REFERÊNCIAS}

ABBAGNANO, N. Dicionário de Filosofia/ Nicola Abbagnano; tradução da 1. ed. Brasileira coordenada e revista por Alfredo Bossi; revisão da tradução e tradução de novos textos por Ivone Castilho Benedetti, 5. ed. São. Paulo: Martins Fontes, 2007.

AQUINO, Felipe. Educar pela conquista e pela fé. Cidade (2019).

BRASIL. Lei de Diretrizes e Bases da Educação Nacional (LDBEN). Lei nº 9.394, de 20 de dezembro de 1996. MEC, 1996. Disponível em: <http:/ / www.planalto.gov.br/ ccivil_03/leis/19394.htm>. Acesso em 18 abr. 2019.

CAIADO, Elen Campos. A Importância da parceria Família e Escola. Disponível em: <https:/ / educador.brasilescola.uol.com.br/sugestoes-pais-professores/aimportancia-parceria-familia-escola.htm>. Acesso em: 18 abr. 2019.

CURY, Augusto Jorge. 20 regras de ouro para educar filhos e alunos: como formar mentes brilhantes na era da ansiedade. São Paulo, 2017.

CURY, Augusto Jorge. Pais brilhantes, professores fascinantes. Rio de Janeiro: Sextante, 2003.

FILIPAK, Sheila Patrícia. Indisciplina e ato infracional: desafios no cotidiano escolar. Irati - Paraná, 2016/2017.

FURTADO, Júlio. Relação Escola-Família: uma questão de gestão. 2015. Gestão educacional. Disponível em: <http:/ / www.juliofurtado.com.br/julio>. Acesso em: 26 out. 2019.

GIL, A. C. Como elaborar projetos de pesquisa. 5. ed. São Paulo-SP: Atlas, 2010.

LEITE, Sérgio Antônio da Silva. Afetividade nas práticas pedagógicas. Temas em Psicologia, vol. 20, n 2, 355 - 368, 2012. Disponível em: <http:/ / pepsic.bvsalud.org/ pdf/tp/v20n2/v20n2a06.pdf >. Acesso em 16 abr. 2020.

MAHONEY, Abigail Alvarenga; ALMEIDA, Laurinda Ramalho de. Afetividade e processo ensino-aprendizagem: contribuições de Henri Wallon. Psicologia da educação. n. 20, São Paulo, jun. 2005. Disponível em: <http:/ / pepsic.bvsalud.org/ scielo.php?script=sci_arttext\&pid=S1414-69752005000100002>. Acesso em 18 abril de 2020.

OLIVEIRA, Rui de (Ed.). Domine sua agressividade interior e liberte o seu gênio para o sucesso. 2006

PILETTI, Nelson. Psicologia educacional. São Paulo: Ática, 1993.

PPP. Projeto Político Pedagógico. Colégio Millennium. Confresa/MT, 2017. 
RIBEIRO, Marinalva Lopes. A afetividade na relação educativa. Estudos de Psicologia, 27(3), p. 403-412, 2010. Disponível em: <http:/ / www.scielo.br/pdf/ estpsi/v27n3/12.pdf >. Acesso em 16 abr. 2020.

ROTENBERG, Izrael. Fragmentos da sabedoria universal. Biblioteca Nacional, 2011. Disponível em: <http:/ / www.filhos.topsites.bz/educacao/Izrael-RotenbergFragmentos-da-Sabedoria-Universal.pdf>. Acesso em: 18 abr. 2019.

SCHWYZER, Ingrid. Vida familiar em diferentes tempos. 1. Ed. Curitiba: Positivo, 2011.

STEINBERG, Laurence (Ed.). Dez princípios básicos para educar seus filhos. 2005. Disponível em: <http://www.filhos.topsites.bz/educacao/Estudo-do-Livro-10principios-basicos-para-educar-seus-filhos.pdf>. Acesso em: 19 out. 2019

ZAGURY, Tania. Limites sem trauma - Construindo cidadãos. 1991. 